\title{
SACOLAS ECOLÓGICAS: Um desafio cultural do Marketing Verde
}

\section{ECOLOGICAL BAGS: A cultural challenge of Green Marketing}

\author{
Thiago Rafael Ferreira Marques ${ }^{1}$; Rudimar Antunes da Rocha ${ }^{2}$; Andreas Dittmar Weise ${ }^{3}$ \\ Andréa Cristina Trierweiller ${ }^{4}$ \\ ${ }^{1}$ Universidade Federal de Santa Catarina - Florianópolis (SC) - Brasil \\ thgmarques16@,hotmail.com \\ ${ }^{2}$ Universidade Federal de Santa Catarina - UFSC - Florianópolis (SC) - Brasil \\ rrudimar@hotmail.com \\ ${ }^{3}$ Universidade Federal de Santa Catarina - UFSC - Florianópolis (SC) - Brasil \\ mail@adweise.de \\ ${ }^{4}$ Universidade Federal de Santa Catarina - UFSC - Florianópolis (SC) - Brasil \\ andreatri@gmail.com
}

\begin{abstract}
Resumo
Muito se tem falado sobre ecologia, mas na esfera organizacional essa polêmica tem causado controvérsias. Principalmente, no que se refere ao uso de sacolas plásticas versus ecobags ou sacolas ecológicas. Para entender melhor esta questão, resolveu-se averiguar clientes de um supermercado de bairro situado na Cidade de Florianópolis (SC). O objetivo foi identificar as razões e a conscientização dos clientes do supermercado Comper - Trindade, visando a identificação do que favorece ou prejudica a utilização de sacolas ecológicas pelos clientes, bem como a consciência ecológica neste caso. O estudo de caso foi realizado no mês de maio de 2009 com os clientes no interior deste estabelecimento varejista. Foram entrevistados 205 clientes, através de um questionário semi-estruturado, em que o foco era identificar que utilizava e porque fazia isso e quem não usava ecobags e as causas para essa decisão. A pesquisa abordou aspectos teóricos relacionados a marketing ecológico e ao comportamento do consumidor. Identificou-se que mais de $30 \%$ dos clientes deste supermercado já utilizam as sacolas ecológicas constantemente, mesmo sem haver uma política de comunicação e sensibilização de marketing ecológico adotado pela referida empresa. Conclui-se que as ações de marketing adotadas pelo Comper - Trindade (Florianópolis/SC) pode ser reforçada para ampliar a utilização desta embalagem ecológica ou ecobag, devido o seu cliente ter um elevado nível educacional $e$ econômico que pode contribuir com este objetivo.
\end{abstract}

Palavras-chave: eco-marketing; sacolas ecológicas; supermercado.

\section{Introdução}

A preocupação com o meio ambiente é um tema com crescentes discussões acadêmica e social. O surgimento de ONGs atuantes neste segmento e o apoio de meios de comunicação de massa têm fortificado a necessidade de ações que contemplem medidas práticas na proteção da 
poluição do planeta. A legislação brasileira ainda não tem medidas definidas para algumas atividades poluidoras do ambiente, mas avanços consideráveis nas esferas estaduais têm emergido. Um desses avanços ecológicos está associado à diminuição ou eliminação da utilização de sacolas em plástico por sacolas ecológicas ou biodegradáveis em supermercados. A polêmica sobre esta questão é elevada e, ainda, encontra resistências que precisam de fortes apelos de comunicação, através de campanhas de marketing verde ou eco-marketing.

As sacolas plásticas tradicionais utilizadas largamente em supermercados e no comércio em geral têm como base o petróleo na sua fabricação. Milhões deste tipo de sacolas são produzidos anualmente, a fim de satisfazer a grande demanda do consumidor tradicional. A utilização do petróleo para a manufatura de produtos, por si só, já é causadora de grandes problemas ambientais, pois contribui na poluição do ar, na emissão de carbono na atmosfera, na degradação da fauna nos locais de extração, dentre outros. Há também o problema do descarte inadequado destas sacolas. Se descartadas de forma incorreta, as sacolas podem acarretar problemas como, por exemplo, o bloqueio do escoamento sanitário e danos a fauna e flora local.

Dentro deste raciocínio é que foram criadas ou resgatadas as ecobags ou sacolas ecológicas, visando à substituição gradativa das sacolas de plástico. A conscientização para essa mudança tem sido largamente divulgada por meio de ações que endereçam à diminuição do uso de sacolas plásticas com apelos à preservação ecológica como marketing institucional em simbiose ao marketing verde ou eco-marketing.

Ciente da relevância do tema viu-se por bem realizar um estudo que sinalizasse para as questões que têm sido decisivas para a utilização ou resistência ao uso de sacolas ecológicas no varejo em Florianópolis (SC). O objetivo foi identificar os principais fatores que influenciam a decisão do cliente de um Supermercado de Florianópolis utilizar sacolas ecológicas no transporte de suas compras.

\section{Metodologia}

A literatura especializada adverte que existem diversas formas de se classificar uma pesquisa. Quanto à finalidade, pode-se classificar a pesquisa em pura ou prática (MARCONI; LAKATOS, 2007). A pesquisa pura é aquela em que se adquire conhecimento sem que haja uma aplicação prática prevista. Já a pesquisa prática, como o próprio nome diz, é a aplicação dos conhecimentos adquiridos na solução de problemas concretos na vida real. Portanto, com base nas definições colocadas, pode-se dizer que a presente pesquisa é classificada como prática, haja vista que tem o objetivo a resolução de um problema encontrado na realidade. 
Por sua vez, quanto aos objetivos, pode-se classificar a pesquisa em exploratória, descritiva e explicativa. A pesquisa exploratória, no entender de Zikmund (2006, p. 125), "pode ser conduzida para diagnosticar uma situação, selecionar alternativas ou descobrir novas idéias“. A pesquisa descritiva, por sua vez, é a descrição de um fenômeno, a observação, registro, análise e correlação de fatos ou fenômenos sem manipulá-los (MARCONI; LAKATOS, 2007). E a pesquisa explicativa, "além de registrar, analisar e interpretar os fenômenos estudados tem como preocupação primordial identificar os fatores que determinam ou contribuem para as ocorrências de fenômenos, isto é, suas causas. Este é o tipo de pesquisa que mais aprofunda o conhecimento da realidade, porque explica a razão e o porquê das coisas“ (UNILESTE-MG, 2005).

Após a análise bibliográfica foi realizado um levantamento de dados primários a partir da aplicação de uma entrevista estruturada em uma amostra aleatória da população (Figura 1). De acordo com a classificação de Marconi e Lakatos (2007), tal pesquisa consiste em uma entrevista estruturada, sendo aquela em que o entrevistador segue um roteiro estabelecido com perguntas previamente definidas.

O universo da pesquisa foi à população residente nos Bairros Trindade, Pantanal e Serrinha (Florianópolis-SC). A amostra foi constituída de 205 clientes do supermercado Comper Trindade com erro amostral de 7\%. A amostragem foi definida com intuito de se obter uma confiabilidade de 93\% da amostra. As entrevistas foram realizadas no interior do referido estabelecimento e realizadas no mês de maio de 2009.

\section{Marketing verde ou eco-marketing}

O marketing ecológico, eco-marketing ou marketing verde é uma tendência estratégica das diversas organizações contemporâneas e que vem tomando grandes proporções nas duas últimas décadas. O cerne do marketing ecológico é sensibilizar as pessoas jurídicas e físicas para a preocupação com a saúde e o bem-estar da população. Ele vem se tornando assunto obrigatório na "vida cotidiana" dos dirigentes organizacionais, pois associam conceitos relevantes de preservação da natureza com as estratégias de marketing empresarial. Esta nova concepção começa a dar resultados nas empresas modernas, como por exemplo, Boticário, Natura, AMBEV.

A preocupação com o meio ambiente é uma grande preocupação social que afeta o mundo inteiro. Esta causa acaba vem criando desafios aos profissionais do marketing contemporâneos. Haja vista, que à medida que as barreiras comerciais diminuem e a globalização se expande, as questões ambientais vão tendo um impacto maior sobre o comércio internacional. Dentro deste raciocínio, diversos países ao redor do mundo estão desenvolvendo barreiras regulamentares ambientais extremamente rigorosas, que de adaptam aos regulamentos e expectativas locais dos 
consumidores (KOTLER; ARMSTRONG, 1998). Dentro deste panorama, os produtos passam a ser avaliados não somente com base em seu desempenho ou preço, mas na responsabilidade sócioecológico dos fabricantes. O valor do produto inclui fatores como a salubridade ambiental do produto e embalagem. Assim, a qualidade passou a incorporar a imagem ecológica da empresa que não mais se separa do seu impacto ambiental (OTTMAN, 1992). Por esta razão, o marketing verde proporciona as empresas uma chance de influenciar de forma positiva a imagem da organização frente aos seus consumidores, abrir novos mercados e criar diferencial competitivo.

\subsection{Princípios}

O marketing ecológico pode ser tomado como uma forma de comercialização voltada para uma causa social. Sobre esta afirmação, Melo (2002) deixa claro que a concepção de marketing verde esta interligada com a filosofia do marketing societal, na medida em que são estratégias importantes para o atingimento de um objetivo uniforme: a qualidade do produto para a saúde do consumidor. Referente ao marketing verde, a ação da empresa voltada para a gestão ambiental não se limita a apenas oferecer produtos ecologicamente corretos, mas passa também pelas operações da própria indústria. Kotler e Armstrong (1998) reforçam esta idéia ao afirmar que as empresas compromissadas com o "verde" devem evitar a poluição do ecossistema. O verdadeiro trabalho "verde" exige que se pratique uma administração de "três Rs" em termos de lixo: reduzir, reusar e reciclar.

O marketing verde é uma forma de atingir os desejos dos consumidores, Ottman (1994) afirma que os consumidores considerados "verdes" agem motivados por necessidades universais. Estas necessidades se traduzem em novas estratégias de compra, trazendo profundas implicações na maneira como os produtos são desenvolvidos e comercializados.

\subsection{Aplicabilidade}

As empresas focadas na utilização do marketing verde como vantagem competitiva, devem estar atentas a movimentação do mercado. Apesar da crescente movimentação em apoio a este tipo de abordagem, a aplicação dos conceitos acaba por criar necessidades de investimento que podem acabar por trazer dificuldades dentro de um mercado voraz e competitivo. De forma a ter o impacto desejado nos consumidores, os princípios do marketing verde devem ter sua aplicação concisa dentro de um contexto de desenvolvimento ou aprimoramento de produto. Ottman (1994) agrupa as questões de produtos ambientalmente corretos em quatro áreas e subseqüentes divisões:

- Aquisição e processamento de Matérias-Primas; 
- Questões de Produção e Distribuição;

- Questões de uso de produto e embalagens; e

- Questões de uso posterior/descartabilidade.

Observa-se claramente que a adequação de produtos dentro de um contexto de sustentabilidade é um caminho dispendioso para a empresa. Porém, ao passo que a empresa opte por tornar-se "verde", a imagem criada por este fato e o vinculo direto que é formado com o consumidor fazem com que o investimento de capital financeiro fique em segundo plano. É válido lembrar ainda que, como cita Ottman (1994), o desenvolvimento de processos e produtos ambientalmente corretos oferece uma rara oportunidade para os profissionais integrarem seus próprios valores dentro do ambiente de trabalho. Desta forma, pode-se afirmar que a aplicação do marketing verde traz vantagens dentro de esferas organizacionais, sociais, pessoais e ambientais.

\subsection{Sacolas ecológicas}

Vale relembrar que as sacolas plásticas para a utilização em supermercados e comércio em geral surgiram em 1862. Ela foi uma revolução para o comércio da época pela praticidade e por ser barata. No Brasil, o seu uso se ampliou a partir da década de 1980. Até que a consciência ecológica ganhasse as mídias de massa, como televisão e rádios, essa embalagem sequer era questionada, pois as informações sobre os danos causados no ambiente não eram divulgados. Com o surgimento de ONGs preocupadas e apoiadas pelas mídias internacionais e nacionais que alertaram para os danos em cadeia deste tipo de produto, os questionamentos sobre a sua eficácia e efetividade passaram a ser questionadas. Nos últimos anos da década de 1990, uma grande corrente ecológica ganhou força com o partido verde e outros tipos de interferências governamentais. Assim, esta crescente preocupação ecológica fez com que as pessoas buscassem alternativas que evitasse o uso indiscriminado das sacolas plásticas.

Informações fornecidas pela Agência de Proteção Ambiental dos Estados Unidos revelam que são consumidos anualmente entre 500 bilhões e um trilhão de sacos plásticos ao redor do mundo e apenas 1\% desta quantia é reciclada. Além disso, um estudo de 1975 demonstrou que as embarcações transoceânicas lançam, aproximadamente, 4 milhões de quilogramas de plástico ao mar por ano. As lixeiras do mundo não estão inundadas de plástico porque a maior parte do plástico acaba no oceano. Sendo assim, o plástico é um problema ambiental grave, já que influi diretamente da vida marinha, levando a morte cerca de 200 delas incluindo baleias, tartarugas, focas dentre outras (CBC AMBIENTAL, 2009).

Diante de dados tão alarmantes acerca do dano ambiental das sacolas derivadas de petróleo, nota-se a necessidade de novas alternativas que substituam as mesmas. Uma das alternativas 
encontradas para este fim é o uso de sacolas ecológicas. As sacolas ecologicamente corretas são feitas essencialmente de tecidos que não afeta negativamente o meio ambiente, estes podem ser de lonita pan, juta, lona pet reciclada, algodão, dentre outros (ECOLOGICPACK, 2009).

A partir destas informações pode se perceber a repercussão do assunto no tangente à proteção ao meio ambiente. É evidente que cada vez mais as pessoas estão usando sacolas plásticas pela sua aparente disponibilidade, porém não sabem o mal que estão causando ao meio em que todos os seres vivos. Nesse contexto, está inserida a questão da substituição das sacolas provenientes do petróleo por sacolas chamadas ecológicas.

\section{Comportamento do Consumidor}

Dada a sociedade em que se vive, todas as pessoas ao redor do planeta constituem-se em consumidores. Diariamente, consomem-se alimentos, moradias, transportes, dentre tantos outros fatores essenciais para a vida do ser humano. As decisões que os indivíduos tomam diariamente acerca do comportamento de consumo afetam diretamente a economia como um todo. Schiffman e Kanuk (1997) reforçam esta idéia ao dizer que o comportamento do consumidor é um fator integral no fluxo de negócios de uma sociedade orientada ao consumo.

Peter e Olson (2009) sinalizam que para o entendimento dos conceitos a respeito do comportamento do consumidor, é fundamental que o comportamento do consumidor seja dinâmico, por interações e é determinado por trocas. Analisando os conceitos apresentados, pode-se observar que o estudo do comportamento do consumidor aprofunda-se no cerne do entendimento de um processo psicológico, onde a decisão de consumo é afetada pelas mais diversas variáveis externas. A função principal de um gestor de marketing sobre a abordagem comportamental foca-se não somente nos fins deste processo, mas também em seu início e desenvolvimento. A complexidade do tema cria uma área de estudo vasta e rica em informações, cuja compreensão e aplicabilidade formam pilares essenciais ao desenvolvimento de estratégias mercadológicas.

\subsection{Processo de decisão do consumidor}

Os estudos referentes ao comportamento do consumidor visam como foco prático, entender todo o processo de decisão de consumo do cliente. Analisando por este prisma, tem-se como grande tema de estudo o momento em que um consumidor opta por um produto ou serviço. $\mathrm{O}$ entendimento acerca o assunto mostra-se de suma importância para o marketing.

Destaca-se, que dentro de um processo de decisão é extremamente variável, tendo em vista que cada decisão é única e possui características diversas. Hawkins, Mothersbaugh e Best (2007, p. 
291) observam que o processo de compra muda à medida que o envolvimento com a compra aumenta. O processo de tomada de decisão de consumo é diretamente ligado aos fatores que os influenciam. A junção do entendimento deste processo com as estratégias para influir na decisão formam uma ferramenta poderosa para atingir os consumidores de forma eficaz e eficiente.

\subsection{Influências no comportamento do consumidor}

Dentre os vários fatores que influenciam no comportamento do consumidor, Kotler e Armstrong (1998) destacam que as características culturais, sociais, pessoais e psicológicas são altamente relevantes na decisão de compra. Desta forma, as pessoas normalmente tentam satisfazer a necessidade mais premente, e assim que esta esteja satisfeita, essa necessidade deixará de ser motivadora e surgirá uma nova necessidade premente. Tendo em vista os fatores que influenciam o comportamento do consumidor, o profissional de marketing tem como importante tarefa ter o seu pleno entendimento, de forma a moldar as estratégias aplicadas ao consumidor e analisar de forma clara até que ponto seus esforços estão influenciando na decisão de consumo.

\subsection{Variações culturais do comportamento}

A influência da cultura nos padrões de consumo é claro e como afirmam Hawkins, Mothersbaugh e Best (2007), a estratégia de marketing é altamente influenciada por fatores culturais como valores, fatores demográficos e idiomas. A abordagem do marketing frente da cultura de um povo deve ser focada na diversidade existente, criando dessa forma, estratégias que se adaptem aos modelos previamente estudados de uma cultura local, seja aplicada a um país seja aplicada a uma cidade ou a uma família. O estudo desta aplicação influencia de forma direta no posicionamento e diferenciação que um produto apresenta em seu mercado.

Aplicando-se o conceito de diferenciação de padrões de consumo relacionado a fatores culturais, pode-se analisar a relação e visão do consumidor em relação à natureza. Claramente a visão de culturas diferentes é distinta acerca do desenvolvimento sustentável. Dentro deste raciocínio, Hawkins, Mothersbaugh e Best (2007) salientam que a maioria dos países europeus do norte dá muito valor ao meio ambiente, ao contrário dos norte-americanos que possuem uma visão histórica de que a natureza é algo a ser dominada e melhorada. Essas diferenças nas atitudes em relação ao meio ambiente se refletem nas decisões de compra e nas práticas de consumo.

\section{Análise dos resultados}


Descritas as relações teóricas inerentes ao estudo realizado, cabe apresentar os resultados da pesquisa desenvolvida no Supermercado Comper - Trindade Florianópolis (SC). Os resultados foram divididos em: análises das variáveis selecionadas e cruzamento destas variáveis.

\subsection{Análises das variáveis individuais}

As variáveis consideradas ou classificadas como individuais no estudo foram: Sexo do respondente; escolaridade do entrevistado; sua renda familiar; se o respondente já utiliza sacola ecológica; quais fatores motivam a utilização deste tipo de sacola; o que pode estimular o uso de sacolas ecológicas; fatores que levam a não utilizar esse tipo de embalagem; até quanto estaria disposto a pagar por uma sacola ecológica; e, consciência ecológica que se resolveu estabelecer alguns critérios de compreensão dos termos inerentes a preservação do ecossistema e informações sobre o fenômeno ecológico atual.

\subsubsection{Sexo}

Da amostra estabelecida em 205 entrevistados, o resultado da pesquisa indicou que 53,17\% dos questionados são do sexo feminino e, claro, os demais $46,83 \%$ do público analisado pertencem ao sexo masculino. Conseguiu-se com isso um equilíbrio entre os sexos dos questionado, evitandose possíveis vieses sobre o que poderia pensar o público masculino e feminino sobre as questões ecológicas analisadas. O cuidado com a abordagem e a utilização do mesmo questionário impresso em cores de papel diferente contribuiu com esse fato, onde os questionários impressos em folhas brancas foram aplicados aos clientes do sexo feminino e os questionários impressos em folhas azuis para os respondentes masculinos.

\subsubsection{Escolaridade}

Como salientado anteriormente, o estabelecimento pesquisado situa-se em um bairro com predominância de estudantes universitários. Este fato pode ter contribuído para que a maioria dos respondentes, isto é, mais de 95\% dos questionados terem cursado curso superior ou estejam cursando esta modalidade de educação. Assim, 39,02\% dos entrevistados possuem o ensino superior incompleto, enquanto que mais da metade $(64,39 \%)$ dos entrevistados tiveram contato com o ensino superior de alguma forma e menos de $5 \%(4,88 \%)$ da amostra tem apenas o ensino fundamental incompleto. 


\subsubsection{Renda dos entrevistados}

A renda dos entrevistados foi uma das curiosidades que se buscou identificar para se poder ter o perfil dos entrevistados, que está retratada na Tabela 01 . Verificou-se que 44,39\% dos entrevistados recebem até R\$ $1.000,00$ por mês. Por sua vez, 33,66\% têm uma remuneração que oscila de $\mathrm{R} \$ 1.001,01$ até $\mathrm{R} \$ 3.000,00$. Os respondentes que salientaram receber de $\mathrm{R} \$ 3.000,01$ até $\mathrm{R} \$ 5.000,00$, ficou na casa dos 9,27\%. Já, 6,34\% dos entrevistados disseram que sua remuneração está na faixa que vai de $\mathrm{R} \$ 5.000,01$ até 7.000,00. Cerca de, 4,39\% que assinalaram receber mais do que $\mathrm{R} \$ 7.000,00$, enquanto que $1,95 \%$ dos entrevistados preferiram não responder esta pergunta.

Tabela 1 - Renda dos entrevistados

\begin{tabular}{|c|c|c|c|}
\hline \multirow{2}{*}{ Renda } & \multirow{2}{*}{ Quantidade } & \multicolumn{2}{|c|}{ Frequência } \\
\hline & & Relativa & acumulada \\
\hline Até $\mathrm{R} \$ 1.000,00$ & 91 & $44,39 \%$ & $44,39 \%$ \\
\hline De R\$ $1.000,01$ até $\mathrm{R} \$ 3.000,00$ & 69 & $33,66 \%$ & $78,05 \%$ \\
\hline De $\mathrm{R} \$ 3.000,01$ até $\mathrm{R} \$ 5.000,00$ & 19 & $9,27 \%$ & $87,32 \%$ \\
\hline De $\mathrm{R} \$ 5.000,01$ até $\mathrm{R} \$ 7.000,00$ & 13 & $6,34 \%$ & $93,66 \%$ \\
\hline Acima de $\mathrm{R} \$ 7.000,00$ & 9 & $4,39 \%$ & $98,05 \%$ \\
\hline Não responderam & 4 & $1,95 \%$ & $100,00 \%$ \\
\hline Total & 205 & $100,00 \%$ & \\
\hline
\end{tabular}

Fonte: Dados Primários, 2009

\subsubsection{Utilização de sacolas ecológicas}

Como o estudo foi endereçado para se identificar os clientes do Supermercado Comper que utilizavam as sacolas ecológicas foi indispensável averiguar quais respondentes que utilizam esse tipo de embalagem. Os dados percentuais foram de que 68,29\% dos entrevistados utilizam as sacolas plásticas não ecológicas em suas compras e, somente $31,71 \%$ disseram usarem as sacolas ecológicas para o armazenamento e transportes de suas compras no referido estabelecimento, conforme se pode verificar na Tabela 02 .

Tabela 2 - Utilização de sacolas ecológicas

\begin{tabular}{cccc}
\hline Utiliza sacola ecológica & Quantidade & Relativa & Acumulada \\
\hline Sim & 65 & $31,71 \%$ & $31,71 \%$ \\
Não & 140 & $68,29 \%$ & $100,00 \%$ \\
Total & $\mathbf{2 0 5}$ & $\mathbf{1 0 0 , 0 0 \%}$ & - \\
\hline
\end{tabular}

Fonte: Dados Primários, 2009 
Destaca-se o fato ser somente um terço dos entrevistados que usam as sacolas ecológicas em suas compras. Esses dados têm duas formas de análise: de um lado é preocupante por ser elevado o percentual de usuários que ainda utilizam as sacolas tradicionais de plástico que são posteriormente descartáveis e poluem o ecossistema. Do outro lado, os dados são surpreendentes porque poucas ações de marketing verde são utilizadas no referido supermercado, podendo-se supor o elevado grau de consciência voluntária de alguns usuários, mesmo que este percentual não seja ainda o desejado.

Assim, admite-se que um esforço concentrado em lembrança dos clientes para os cuidados com o ecossistema, através de marketing ecológico pode ser muito positivo e o supermercado obter melhores resultados e retornos favoráveis a sua imagem corporativa e, principalmente, ao ecossistema. Deve-se lembrar que os clientes deste e dos demais supermercados da grande Florianópolis residem em uma ilha que endereça todos os seus resíduos ao mar e, portanto, de forma direta ou indireta ao planeta.

\subsubsection{Fatores que motivam o uso das sacolas ecológicas}

Identificado o percentual de respondentes que assinalaram o hábito de utilizarem as sacolas ecológicas em suas compras, buscou-se conhecer as causas predominantes para essa decisão, como pode ser visto na Tabela 03. Dos fatores que motivam as pessoas a usarem as sacolas ecológicas, identificou-se que $9,23 \%$ dos respondentes indicaram que o conforto era o fator primordial. Já, $7,69 \%$ dos usuários de sacolas ecológicas citaram ser a capacidade de armazenamento o fator essencial. A preocupação com a saúde ficou na casa dos 3,08\% dos respondentes. Porém, 80\% desses usuários assinalaram que têm preocupações com o meio ambiente, reforçando o aspecto voluntário de decisão sobre a mudança de comportamento destes consumidores, pois como se ressaltou são raras as ações de marketing ecológico adotadas pela organização supermercadista que serviu de laboratório desta pesquisa. No computo geral esses dados são positivos, haja vista que permite supor que há uma consciência ecológica nestes usuários que não pode ser considerado apenas um modismo.

Tabela 3 - Fatores que motivam o uso das sacolas ecológicas

\begin{tabular}{|c|c|c|c|}
\hline \multirow{2}{*}{ Fatores que motivam o uso de sacolas ecológicas } & \multirow{2}{*}{ Quantidade } & \multicolumn{2}{|c|}{ Frequência } \\
\hline & & Relativa & Acumulada \\
\hline Conforto & 6 & $9,23 \%$ & $9,23 \%$ \\
\hline Capacidade de armazenamento & 5 & $7,69 \%$ & $16,92 \%$ \\
\hline Preocupação com a saúde & 2 & $3,08 \%$ & $20,00 \%$ \\
\hline Preocupação com o meio ambiente & 52 & $80,00 \%$ & $100,00 \%$ \\
\hline Total & 65 & $100,00 \%$ & - \\
\hline
\end{tabular}

Fonte: Dados Primários, 2009 


\subsubsection{Fatores que levam a não utilizar as sacolas ecológicas}

No estudo foi identificar os principais fatores apontados pelos os clientes do Supermercado Comper não utilizarem as sacolas ecológicas em suas compras. Estes dados podem ser visualizados na Tabela 4. Obteve-se que 52,14\% dos entrevistados disseram que não utilizam essas embalagens por força do hábito. Vale salientar que alguns supermercados não permitem seus clientes circulem com sacolas no interior de suas lojas. Por sua vez, 2,14\% dos entrevistados que não utilizam as sacolas ecológicas em suas compras, isto é, preferem as sacolas de plástico descartáveis, afirmaram que o preço destas sacolas decisivo é elevado e nem sempre duradouras. Já, 25,71\% indicaram a falta de praticidade, pois nem sempre programam a ida a esses estabelecimentos comerciais. Essa razão é um fato cultural inegável, pois a entrada em um supermercado muitas vezes ocorre por uma necessidade específica ou pela passagem no estabelecimento. No entanto, 5\% salientaram ser difícil utilizar estas sacolas nas compras grandes, pois exigiria várias sacolas ecológicas. Esta declaração também é um fator negativo a prática das sacolas ecológicas, pois quando a compra é elevada são necessárias várias sacolas de modo a se separar as compras por gêneros de produtos. Verificou-se ainda que $15 \%$ dos respondentes que não utilizam as sacolas ecologia destacaram outros aspectos culturais e pessoais peculiares a compras em supermercados.

Tabela 4 - Fatores que levam a não utilizar sacolas ecológicas

\begin{tabular}{lrrr}
\hline \multicolumn{1}{c}{ Fatores que levam a não utilizar } & Quantidade & \multicolumn{2}{c}{ Frequência } \\
& Relativa & Acumulada \\
\hline Força do hábito & 73 & $52,14 \%$ & $52,14 \%$ \\
Preço da sacola ecológica & 3 & $2,14 \%$ & $54,29 \%$ \\
Praticidade da sacola de plástico & 36 & $25,71 \%$ & $80,00 \%$ \\
Dificuldade de realizar grandes compras com a sacola ecológica & 7 & $5,00 \%$ & $85,00 \%$ \\
Outros (Usar como sacola de lixo; fato de não ter uma; dificuldade de & 21 & $15,00 \%$ & $100,00 \%$ \\
ver benefícios; disponibilidade). & 140 & $100,00 \%$ & \\
\hline \multicolumn{1}{c}{ Total } & &
\end{tabular}

Fonte: Dados Primários, 2009

\subsubsection{O que estimularia a utilizar as sacolas ecológicas}

Teve-se também a preocupação de descobrir o que poderia estimular a utilização das sacolas ecológicas pelos respondentes que não tem essa prática ainda. Pelos dados coletados, descobriu-se que $24,29 \%$ dos entrevistados seriam estimulados a usar as sacolas ecológicas em suas compras se elas fossem gratuitas. Esta resposta reforça os dados indicados na Tabela 04. Obteve-se que 31,43\% dos respondentes têm a preocupação com o meio ambiente como fator; 26,43\% usaria se tivesse acesso fácil as sacolas ecológicas. Essa resposta foi interessante, porque se pode verificar que as 
sacolas ecológicas para vendas no supermercado estudado, realmente não está em um lugar visível ou com algum tipo de atrativo que chame atenção dos seus clientes. Os dados apontaram também que $4,29 \%$ dos respondentes destacaram que usaria as ecobags pelo conforto, enquanto que 3,57\% pela capacidade de armazenamento. Por sua vez, $2,86 \%$ dos respondentes salientaram que passariam a utilizar as sacolas ecológicas pela preocupação com a saúde. Outros 7,14\% evidenciaram vários motivos como: higiene e legislação. Pode-se verificar a consciência ecológica destacada como fator essencial às decisões de utilização este tipo de embalagem nas compras, mesmo sendo elevado o fator econômico desta relação.

É válido notar que quase um quarto desta amostra utilizaria mais sacolas ecológicas se tivessem mais acesso à mesma. A difusão deste meio de preservação ainda é pouca, e a oferta de sacolas se encontra em níveis abaixo do aceitável. A porcentagem de pessoas que utilizariam as sacolas ecológicas deixa claro que a mudança no comportamento do consumidor em relação às sacolas pode ser alterada com estímulos externos.

\subsubsection{Até quanto você pagaria por uma sacola plástica}

A partir dos dados da pesquisa, percebe-se que $66,34 \%$ dos entrevistados pagariam até $\mathrm{R} \$$ 0,05 por sacola se a mesma fosse cobrada, enquanto que $14,63 \%$ pagariam até $\mathrm{R} \$ 0,10,6,83 \%$ até $\mathrm{R} \$ 0,15 ; 6,83 \%$ até $\mathrm{R} \$ 0,20,4,39 \%$ até $\mathrm{R} \$ 1,00$ e $0,98 \%$ até $\mathrm{R} \$ 5,00$. Destes dados, pode-se tirar a conclusão de que mais da metade $(66,34 \%)$ das pessoas pagaram o valor mínimo que foi apresentado, menos de R $\$ 0,05$. Mais de $80 \%$ (80,98\%) das pessoas pagariam menos de R 0,10 , o que reflete a indisposição dos clientes em trocar as sacolas plásticas por dinheiro. Este dado é reforçado pela quantidade ínfima, menos de 1\% (0,98\%), de pessoas que responderam que pagariam um valor acima de $\mathrm{R} \$ 5,00$.

\subsubsection{Consciência ecológica}

A Tabela 05 oferece a possibilidade de visualizar as ações ecológicas que os respondentes afirmaram utilizar no seu dia-a-dia. Pode-se observar que $89,27 \%$ dos entrevistados afirmaram que economizam água; $86,34 \%$ economizam energia elétrica; $59,02 \%$ fazem coleta seletiva de lixo; $30,73 \%$ reciclam o óleo comestível; $57,56 \%$ usam produtos biodegradáveis na higiene residencial; e, 70,73\% evitam o uso do carro de forma diária para não poluir o ambiente. Salienta-se que o uso do carro precisa de uma informação complementar: grande parte dos clientes deste supermercado é residem em uma área geográfica circunvizinha. Além disso, cabe dizer a grande maioria economiza água e energia elétrica $(89,27 \%$ e $86,34 \%$ respectivamente), talvez pelo custo deste tipo de serviço 
público. Por sua vez, ainda é pouco o percentual de clientes deste estabelecimento que destacaram reciclar o óleo de cozinha (30,73\%). Esta reduzida percentagem pode estar associada à falta de acesso aos pontos de coletas ou até mesmo ao desconhecimento desta ação ecológica.

Tabela 5 - Consciência ecológica

\begin{tabular}{|c|c|}
\hline Fator & Incidência \\
\hline Água & $89,27 \%$ \\
\hline Luz & $86,34 \%$ \\
\hline Coleta seletiva de lixo & $59,02 \%$ \\
\hline Reciclagem de óleo vegetal & $30,73 \%$ \\
\hline Produtos Biodegradáveis & $57,56 \%$ \\
\hline Evitar uso do carro & $70,73 \%$ \\
\hline Média da amostra & $65,61 \%$ \\
\hline
\end{tabular}

Fonte: Dados Primários, 2009

\subsection{Análise cruzada dos dados}

Para tentar entender melhor os resultados obtidos no estudo foi necessário cruzar algumas das informações, conforme é apresentado na sequência.

\subsubsection{Idade dos respondentes versus a utilização de sacolas ecológicas}

Conforme mostram os dados apresentados, 31,43\% das pessoas até 20 anos usam a sacola ecológica, enquanto 68,57\% afirmam não usá-la. Das pessoas com idade entre 21 a 25 anos, 22,95\% utilizam sacolas ecológicas, ao passo que 77,05\% não fazem uso da mesma. Já na faixa de pessoas entre 26 a 35 anos, 33,33\% da amostra utiliza as ecobags, enquanto 66,67\% não usam as mesmas.

Já das pessoas que responderam o questionário com idade entre 36 a 45 anos, 45,83\% destas utilizam sacolas ecológicas e 54,17\% não. Por outro lado, dentre os respondentes com idade entre 46 a 55 anos, 32\% fazem uso das sacolas ecológicas, enquanto $68 \%$ ainda não utilizam este tipo de embalagem. Das pessoas com idade entre 56 e 65 anos, teve-se que metade delas usa as sacolas ecologicamente corretas, enquanto a outra metade não. Por fim, 22,22\% das pessoas com mais de 66 anos utilizam as ecobags, e 77,78\% não as utiliza deste tipo de embalagem.

Percebe-se que a faixa etária cujas pessoas mais utilizam sacolas ecológicas é a que corresponde às pessoas entre 56 a 65 anos. Já a faixa etária que mais possui integrantes que não usam as ecobags é a que engloba as pessoas com mais de 66 anos.

\subsubsection{Renda do entrevistado versus a utilização de sacolas ecológicas}


O cruzamento dos dados sobre renda dos entrevistados e a utilização de sacolas ecológicas permitiram verificar que a faixa de renda que corresponde de $\mathrm{R} \$ 5.000,00$ a $\mathrm{R} \$ 7.000,00$ é a que possui a maior incidência de usuários de ecobags. Já, a faixa de renda que tem a menor incidência de usuários de ecobags é a que engloba as pessoas que ganham acima de R \$ 7.000,00 ao mês. Tais dados permitem supor que o poder econômico dos entrevistados interfere na decisão de utilizar ou não sacolas ecológicas o que pode indicar que eles utilizam estas embalagens por estarem em "sintonia" com as informações ecológicas emergentes. A Tabela 06 permite a ver estes dados.

Tabela 6 - Renda dos respondentes versus utilização de sacolas ecológicas

\begin{tabular}{|c|c|c|c|}
\hline Renda\Utiliza Sacolas Ecológicas & Sim & Não & Total geral \\
\hline Até R\$ 1.000,00 & $31,87 \%$ & $68,13 \%$ & $100,00 \%$ \\
\hline De $R \$ 1.000,01$ até $R \$ 3.000,00$ & $26,09 \%$ & $73,91 \%$ & $100,00 \%$ \\
\hline De $\mathrm{R} \$ 3.000,01$ até $\mathrm{R} \$ 5.000,00$ & $42,11 \%$ & $57,89 \%$ & $100,00 \%$ \\
\hline De R $\$ 5.000,01$ até $\mathrm{R} \$ 7.000,00$ & $53,85 \%$ & $46,15 \%$ & $100,00 \%$ \\
\hline Acima de $\mathrm{R} \$ 7.000,00$ & $22,22 \%$ & $77,78 \%$ & $100,00 \%$ \\
\hline Não resposta & $25,00 \%$ & $75,00 \%$ & $100,00 \%$ \\
\hline Total & $31,71 \%$ & $68,29 \%$ & $100,00 \%$ \\
\hline
\end{tabular}

Fonte: Dados Primários, 2009

\subsubsection{A utilização de sacolas ecológicas versus a consciência ecológica}

De acordo com a Tabela 02, percebe-se que das pessoas que utilizam sacola ecológica, $78,46 \%$ possuem um grau de consciência ecológica acima da média de 65,61\% enquanto que $21,54 \%$ possuem o percentual abaixo da media. Em relação às pessoas que não utilizam sacolas ecológicas, nota-se que 63,29\% estão acima da média quando se fala em consciência ecológica. Os dados detalhados podem ser visualizados na Tabela 07.

Tabela 7 - A utilização de sacolas ecológicas versus da consciência ecológica

\begin{tabular}{cccc}
\hline Uso da Sacola $C$ Consciência Ecológica & Acima da Média & Abaixo da Média & Total \\
\hline Usa sacola ecológicas & $78,46 \%$ & $21,54 \%$ & $100,00 \%$ \\
Não usa sacola ecológicas & $63,57 \%$ & $36,43 \%$ & $100,00 \%$ \\
Total & $\mathbf{6 8 , 2 9 \%}$ & $\mathbf{3 1 , 7 1 \%}$ & $\mathbf{1 0 0 , 0 0 \%}$ \\
\hline
\end{tabular}

Fonte: Dados Primários, 2009

\subsubsection{A escolaridade dos respondentes versus a consciência ecológica}

Nota-se a partir destes dados que a faixa de escolaridade que possui índices acima da média é a de superior completo, com quase 90\% (89,19\%). Em contra partida, apenas metade (50\%) das 
pessoas com fundamental incompleto possuem consciência ecológica acima da média. Pode-se evidenciar a partir destes dados que a consciência ecológica está intimamente ligada ao nível de instrução da pessoa.

A maioria das pessoas com ensino superior que possui consciência ecológica acima da média contrasta com a quantidade relativamente baixa $(60 \%)$ de pessoas com pós-graduação que possuem índice de consciência ecológica acima da média. A Tabela 08 permite uma visualização detalhadas destas informações.

Tabela 8 - A escolaridade dos respondentes versus a consciência ecológica

\begin{tabular}{lccc}
\hline \multicolumn{1}{c}{ Escolaridade versus consciência ecológica } & Acima da média & Abaixo da média & Total \\
\hline Fundamental Incompleto & $50,00 \%$ & $50,00 \%$ & $100,00 \%$ \\
Fundamental Completo & $70,00 \%$ & $30,00 \%$ & $100,00 \%$ \\
Médio incompleto & $62,50 \%$ & $37,50 \%$ & $100,00 \%$ \\
Médio completo & $65,71 \%$ & $34,29 \%$ & $100,00 \%$ \\
Superior incompleto & $63,75 \%$ & $36,25 \%$ & $100,00 \%$ \\
Superior completo & $89,19 \%$ & $10,81 \%$ & $100,00 \%$ \\
Pós-graduação & $60,00 \%$ & $40,00 \%$ & $100,00 \%$ \\
& Total & $68,29 \%$ & $31,71 \%$ \\
\hline
\end{tabular}

Fonte: Dados Primários, 2009

Com a exceção das pessoas com fundamental incompleto e com superior completo, a variação percentual entre faixas de escolaridade não é tão grande (até 10\%). O que se deve observar é que as escolaridades que mais possuem índice de consciência elevado são pessoas com superior completo $(89,19 \%)$ e pessoas com ensino fundamental completo $(70 \%)$.

\subsubsection{Renda X consciência ecológica}

É possível perceber, na Tabela 09, que, independentemente da renda, é maior o número de pessoas com consciência ecológica acima da média do que de pessoas com consciência ecológica abaixo da média. Isto indica que parte dos clientes do supermercado Comper Trindade tem grande consciência ecológica.

Tabela 9 - Renda dos respondentes versus a consciência ecológica

\begin{tabular}{lccc}
\hline \multicolumn{1}{c}{ Renda/Consc. Ecológica } & Acima da Média & Abaixo da Média & Total geral \\
\hline Até R \$ 1.000,00 & $65,93 \%$ & $34,07 \%$ & $100,00 \%$ \\
De R \$ 1.000,01 até R\$ 3.000,00 & $66,67 \%$ & $33,33 \%$ & $100,00 \%$ \\
De R \$ 3.000,01 até R\$ 5.000,00 & $78,95 \%$ & $21,05 \%$ & $100,00 \%$ \\
\hline
\end{tabular}




\begin{tabular}{|c|c|c|c|}
\hline De $\mathrm{R} \$ 5.000,01$ até $\mathrm{R} \$ 7.000,00$ & $76,92 \%$ & $23,08 \%$ & $100,00 \%$ \\
\hline Acima de $\mathrm{R} \$ 7.000,00$ & $77,78 \%$ & $22,22 \%$ & $100,00 \%$ \\
\hline Não responderam & $50,00 \%$ & $50,00 \%$ & $100,00 \%$ \\
\hline Total geral & $68,29 \%$ & $31,71 \%$ & $100,00 \%$ \\
\hline
\end{tabular}

Fonte: Dados Primários, 2009

\subsection{Estratégias para ampliação da utilização das sacolas ecológicas no estabelecimento}

Utilizando-se das análises da base de dados formada a partir da pesquisa de mercado, podem-se traçar estratégias mais precisas para a ampliação da utilização de sacolas ecológicas. A aplicação deste estudo na prática visa não somente o retorno financeiro sobre o desuso das sacolas plásticas, mas objetiva fomentar a consciência ecológica aos clientes do supermercado Comper, atender a necessidade destes clientes, bem como agregar valor a sua marca, através do marketing ecológico ou verde.

Desta forma, partindo das informações adquiridas com o estudo, sugerem-se as seguintes estratégias de marketing verde ou eco-marketing para o supermercado Comper Trindade, localizado em Florianópolis (SC): criar facilidades para o acesso às sacolas ecológicas; condicionar o cliente ao hábito de utilizar as ecobags no lugar das sacolas de plástico; oferecer promoções e descontos para quem utiliza sacolas ecológicas; e relacionar a preservação do ambiente com a utilização das sacolas ecológicas. Primeiramente, destaca-se que 26\% da amostra - aproximadamente um quarto da mesma - afirmou que utilizaria mais freqüentemente as sacolas ecológicas se tivesse mais acesso as mesmas.

Por observação direta do estabelecimento, pode-se observar que as sacolas ecológicas não possuem nenhuma forma de destaque dentro do supermercado. Dificilmente um cliente tem contato visual com a mesma dentro do estabelecimento. A oferta física, ou seja, o acesso direto as sacolas, é uma grande barreira para a utilização da mesma, tendo em vista a precariedade da oferta adotada dentro da organização. Observa-se também que durante as entrevistas, muitas pessoas afirmaram não ter conhecimento do oferecimento de sacolas ecológicas, bem como afirmaram desconhecer seu preço e os modelos oferecidos pelo supermercado.

Para atingir o objetivo de ampliar o mercado das sacolas ecológicas, medidas para condicionar o cliente a utilizar as sacolas ecológicas devem ser tomadas. Pode-se citar como estratégias para alcançar esta meta: criação de premiações e bonificações para o uso contínuo da sacola ecológica, visando bonificar o cliente que costumeiramente não utiliza as sacolas de plástico; a cobrança pela unidade de sacolas plásticas é utilizada largamente em comunidades européias, mas é pouco difundida no mercado interno; oferecer sacolas ecológicas de brinde em situações especiais, para difundir mais o seu uso; $24 \%$ da amostra afirmaram que a gratuidade da sacola ecológica é um 
fator que motivaria ao uso; e criar designs diferenciados para as sacolas ecológicas, visando criar modelos que chamem mais a atenção.

Por fim, a associação da consciência ecológica com o uso das ecobags pode ser usada como ferramenta para a ampliação da sua utilização. $32 \%$ dos clientes entrevistados afirmam que o fator que mais o levaria a utilizar a sacola ecológica seria a preocupação com o meio ambiente. Tendo em vista que este assunto encontra-se em pauta na mídia, as pessoas como um todo estão se preocupando cada vez mais com as conseqüências de suas atitudes, e com o impacto que estas atitudes trarão ao meio ambiente que nos cerca. Destaca-se que a sacola ecológica deve ser tratada como uma forma de preservar o meio ambiente. Deve-se associar a utilização constante da ecobag com uma atitude que, apesar da sua simplicidade, impacta de forma intensa na fauna e flor a da região.

As estratégias aqui apresentadas visam a associar o estabelecimento com uma idéia de preocupação com o meio ambiente. A utilização do marketing verde como ferramenta para atingir consumidores é comprovadamente satisfatória, desta forma, o supermercado que tomar atitudes que visem a preservação ambiental, poderá ser relacionado diretamente com esta consciência. A decisão do consumidor passa pela avaliação do estabelecimento em que ocorrerá as compras, e um supermercado que esteja engajado em uma luta contra a degradação ambiental, seja na forma de oferecimento de produtos diferenciados ou no foco na utilização das sacolas ecológicas, pode vir a ser uma escolha acertada para os consumidores que levam o tema a sério.

\section{Considerações finais}

O presente estudo teve por objetivo geral identificar quais os fatores que influenciam no uso das sacolas ecológicas no bairro da Trindade. Nesse sentido, um dos objetivos específicos da pesquisa é a identificação do perfil sócio-econômico dos entrevistados. Por meio de análises estatísticas dos dados coletados no estudo foi possível então identificar tal perfil. Em relação ao delineamento do perfil de consciência ecológica dos entrevistados, pode-se notar que 63,54\% do sexo masculino estão acima da média $(65,61 \%)$ de consciência ecológica, enquanto que as pessoas do sexo feminino apresentam $72,48 \%$ acima da média. Nesse sentido, verifica-se que as mulheres apresentam maior consciência ecológica que os homens.

Das pessoas que utilizam sacolas ecológicas, 78,46\% tem consciência ecológica acima da média. Isto permite admitir que a maioria das clientes do estabelecimento estudado que utiliza sacolas ecológicas em suas compras tem preocupação com o meio ambiente. Pode-se constatar também que 53,85\%, dos usuários de ecobags têm remuneração de R \$ 5.000,01 até R \$ 7.000,00. 
Neste caso se constatou que quanto maior a renda mensal, maior o número de pessoas que usam sacolas ecológicas, com exceção para a faixa acima de R $\$ 7.000,00$, que ficou com taxa de uso abaixo da média. Não foi percebida uma correlação entre o número de pessoas na residência e a taxa de uso das sacolas ambientalmente corretas. Como esperado, a maioria $(78,46 \%)$ dos que usam as sacolas ecológicas apresentam um nível de consciência ambiental acima da média.

Foi constatado que a troca das sacolas plásticas vem recebendo pouca atenção por parte da população e dos estabelecimentos. Embora reportagens sobre o assunto já tenham sido veiculadas em veículos de comunicação de grande porte, na base local o assunto é pouco discutido. Por fim, o preço, embora afete negativamente a demanda por sacolas ecológicas, não parece ser o fator mais decisivo ao não uso das mesmas. Nota-se que os fatores que mais influenciam o uso das sacolas ecologicamente corretas são a força do hábito dos consumidores, já condicionados ao uso das sacolas plásticas, e a pouca acessibilidade às sacolas ecológicas, que são não são oferecidas pelo supermercado ou, quando muito, vendidas em seções separadas.

\begin{abstract}
Much has been said about ecology, but in the organizational sphere this polemic has caused controversy. Mainly, it is in the relation to the use of plastic bags versus ecobags. To better understand this issue, decided to investigate clients of a neighborhood supermarket in the city of Florianopolis (SC). The objective was to identify the reasons for and awareness of customers of the supermarket Comper - Trindade, aiming to identify what helps or harms the use of green bags to customers, as well as ecological awareness in this case. The case study was conducted in May 2009 with customers within this retail establishment. 205 customers were interviewed through a semi-structured questionnaire, in which the focus was to identify who used it and why and who did not use ecobags and the reasons for that decision. The research focuses on theoretical aspects related to eco-marketing and consumer behavior. It was identified that over $30 \%$ of customers of this supermarket that already use green bags constantly, even without a policy of communication and awareness of ecological marketing adopted by that company. Concludes that the marketing actions taken by Comper Trindade (Florianópolis/SC) can be strengthened to expand the use of eco-packaging or ecobag because your customer has a high educational level and economic development that can contribute to this goal.
\end{abstract}

Key-words: eco-marketing; ecological bags, supermarket.

\title{
Referências
}

CBC AMBIENTAL. Loblaws começa a cobrar pelo uso das sacolas plásticas. Disponível em: < http://www.cbcambiental.com.br/noticias.php>. Acesso em: 23 mai 2009.

ECOLOGICPACK. Produtos. Disponível em: <http://www.ecologicpack.com.br/page2.html $>$. Acesso em: 23 mai 2009.

HAWKINS, D. I.; MOTHERSBAUGH, D. L.; BEST, R. J. Comportamento do Consumidor: construindo a Estratégia de Marketing. 10. Ed. Rio de Janeiro: Elsevier, 2007.

KOTLER, P.; ARMSTRONG, G. Principios de Marketing. 7. ed Rio de janeiro: Prentice Hall do Brasil, 1998.

MARCONI, M. de A.; LAKATOS, E. M. Técnicas de Pesquisa: planejamento e execução de pesquisas, amostragens e técnicas de pesquisas, elaboração, análise e interpretação de dados. 6 ed. São Paulo: Atlas, 2007.

OTTMAN, J. Marketing verde. São Paulo: Makron, 1992.

PETER, P. J.; OLSON, J. C. Comportamento do Consumidor e Estratégia de Marketing. 8 ed. São Paulo: Mc Graw-Hill, 2009. 
SCHIFFMAN, L. G.; KANUK, L. L. Comportamento do consumidor. 6.ed. Rio de Janeiro: LTC, 2000.

UNILESTE-MG - CENTRO UNIVERSITÁRIO DO LESTE DE MINAS GERAIS. Estrutura para projetos de pesquisa.

Disponível

em:

<www.unilestemg.br/fapemig/formularios_fapemig/demaisformularios/formestruturaprojetopesqu.doc. 2005.>. Acesso em: 25 maio 2009.

ZIKMUND, W. G. Princípios da pesquisa de marketing. 2 ed. São Paulo: Editora Thomson, 2006.

\section{Dados dos autores:}

Nome completo: Thiago Rafael Ferreira Marques

Filiação institucional: Universidade Federal de Santa Catarina

Departamento: CAD/CSE-UFSC

Função ou cargo ocupado: Aluno da Graduação - Pesquisador NICO

Endereço completo para correspondência (bairro, cidade, estado, país e CEP): Centro Sócio-

Econômico, Departamento de Ciências da Administração, Campus Universitário Professor João

David Ferreira Lima, Sala 225 - NICO (Núcleo de Inteligencia Competitiva Organizacional em

Marketing e Logística), Trindade, Florianópolis, SC, Brasil, CEP: 88040-900

Telefones para contato: (48) 3721-9374 r. 225

e-mail: thgmarques16@hotmail.com

Nome completo: Rudimar Antunes da Rocha

Filiação institucional: Universidade Federal de Santa Catarina

Departamento: Ciências da Administração - NICO

Função ou cargo ocupado: Professor Associado II

Endereço completo para correspondência (bairro, cidade, estado, país e CEP): Avenida Itamaraty, 380, Ap. 202 “C”, Itacorubi, Florianópolis, SC, Brasil, CEP: 88034-400

Telefones para contato: (48) 91011265

e-mail: rrudimar@hotmail.com

Nome completo: Andreas Dittmar Weise

Filiação institucional: Universidade Federal de Santa Catarina

Departamento: Administração - NICO

Função ou cargo ocupado: Pesquisador NICO

Endereço completo para correspondência (bairro, cidade, estado, país e CEP): Rua Joe Collaço, 688, Santa Monica, Florianópolis, SC, Brasil, CEP: 88035-200

Telefones para contato: (48) 96233736 
e-mail: mail@adweise.de

Nome completo: Andréa Cristina Trierweiller

Filiação institucional: Universidade Federal de Santa Catarina

Departamento: Engenharia de Produção

Função ou cargo ocupado: Pesquisadora

Endereço completo para correspondência (bairro, cidade, estado, país e CEP): Rod. Amaro Antônio

Vieira, 2155, Bl. D - Ap. 501, Itacorubi, Florianópolis, SC, Brasil, CEP: 88034-101

Telefones para contato: (48) 99811887

e-mail: andreatri@gmail.com

Recebido para publicação em: 23/08/2010

Aceito para publicação em: 27/11/2010 